OPEN ACCESS

Approved by:

Frontiers Editorial Office Frontiers Media SA, Switzerland

${ }^{*}$ Correspondence:

Frontiers Production Office production.office@frontiersin.org

Specialty section: This article was submitted to Terrestrial Microbiology a section of the journal Frontiers in Microbiology

Received: 02 July 2019 Accepted: 03 July 2019

Published: 16 July 2019

Citation:

Frontiers Production Office (2019) Erratum: Functional Traits and Spatio-Temporal Structure of a Major Group of Soil Protists (Rhizaria: Cercozoa) in a Temperate Grassland. Front. Microbiol. 10:1654 doi: 10.3389/fmicb.2019.01654

\section{Erratum: Functional Traits and Spatio-Temporal Structure of a Major Group of Soil Protists (Rhizaria: Cercozoa) in a Temperate Grassland}

\author{
Frontiers Production Office* \\ Frontiers Media SA, Lausanne, Switzerland
}

Keywords: biogeography, functional traits, soil ecology, protozoa, microbial assembly, environmental selection, dispersal limitation, soil protists

\section{An Erratum on}

Functional Traits and Spatio-Temporal Structure of a Major Group of Soil Protists (Rhizaria: Cercozoa) in a Temperate Grassland

by Fiore-Donno, A. M., Richter-Heitmann, T., Degrune, F., Dumack, K., Regan, K. M., Marhan, S., et al. (2019). Front. Microbiol. 10:1332. doi: 10.3389/fmicb.2019.01332

Due to an editorial error, the Data Availability Statement containing the raw sequences was erroneously omitted from the article. The publisher apologizes for the mistake.

\section{DATA AVAILABILITY}

Raw sequences have been deposited in Sequence Read Archive (SRA, NCBI) SRR6187016 and BioProject PRJNA414535; the 694 OTUs (representative sequences) under GenBank accession \# MG242652-MG243345.

Copyright () 2019 Frontiers Production Office. This is an open-access article distributed under the terms of the Creative Commons Attribution License (CC BY). The use, distribution or reproduction in other forums is permitted, provided the original author(s) and the copyright owner(s) are credited and that the original publication in this journal is cited, in accordance with accepted academic practice. No use, distribution or reproduction is permitted which does not comply with these terms. 